\title{
Retour sur les succès de 2008
}

Dans quelques jours, l'année 2008 fera partie du passé: un moment idéal pour revenir sur les principaux événements qui l'ont marquée du point de vue de la FMH et du corps médical.

\section{Le succès du $1^{\mathrm{er}}$ juin a clairement accru l'influence du corps médical au sein du monde politique}

Les débuts furent plutôt vifs: à peine avait-on adopté et commencé à appliquer les nouveaux modèles de direction de la FMH qu'il s'est agi de combattre le nouvel article $117 \mathrm{a}$ qu'un contre-projet parlementaire voulait introduire dans la Constitution fédérale. Cette lutte a réussi grâce au comité des «professions bleues» fondé par la FMH, et à la campagne efficace que celle-ci a menée avec ses alliés sous la devise «Non au diktat des caisses!». D'autres alliances, notamment avec les cantons, nous ont permis de remporter le $1^{\mathrm{er}}$ juin une victoire à proprement parler historique: le peuple suisse a rejeté massivement le projet parlementaire, par près de $70 \%$ des voix, et ainsi refusé la levée de l'obligation de contracter et un transfert de pouvoir inadéquat en faveur des caisses qui en aurait résulté.

Cette victoire claire a renforcé la position du corps médical sur d'autres thèmes politiquement importants pour lui: je pense à la clause du besoin et à la réglementation qui lui succédera, à l'influence des médecins sur la formation postgraduée et continue, aux baisses de tarif affectant le laboratoire du praticien et la dispensation directe de médicaments, ainsi qu'aux nouveaux modèles d'assurance du type assurance de base duale. Si ces batailles ne sont pas encore toutes gagnées, le succès du $1^{\text {er }}$ juin a clairement accru l'influence du corps médical au sein du monde politique, tout à fait dans la ligne de notre objec- tif stratégique à la fois ancien et nouveau: «Pas de politique de la santé sans la FMH!».

Le succès du $1^{\text {er }}$ juin a eu d'autres effets positifs: la FMH a pu former, au sein des professions de la santé, des alliances qu'elle pourra au besoin réactiver rapidement et en tout temps. Elle a aussi approfondi sa collaboration avec la CDS - un rapprochement qui pourrait s'avérer précieux pour gérer les questions actuelles ou futures concernant notamment la planification des soins.

A l'interne, il faut mentionner les élections générales pour le renouvellement du Comité central de la FMH à fin mai, et la réduction de ce dernier de onze à neuf membres intervenue à cette occasion. Comme on peut déjà le constater après quelques mois, cette mesure a apporté le regain d'efficience qu'on en escomptait. Une des princi-

\section{Le nouveau Comité central a élaboré les objectifs politiques et stratégiques pour la législature 2008-2012}

pales tâches du nouveau Comité a été d'élaborer les objectifs politiques et stratégiques pour la législature 2008-2012, qui ont été approuvés par la Chambre médicale il y a quelques jours: une base solide pour bien aborder la nouvelle année.

$\mathrm{Au}$ terme de cette année riche en événements et en activités, nous vous souhaitons de bonnes et heureuses fêtes et d'agréables journées de détente, afin que nous puissions continuer ensemble en 2009 à repousser avec succès toute attaque contre notre excellent système de santé.

Daniel Herzog, secrétaire général de la FMH 